\title{
PENINGKATAN KEMAMPUAN KOGNITIF SISWA MELALUI PROBLEM BASED LEARNING DENGAN EVALUASI BERBASIS PHYSICS PLAYING CARDS
}

\author{
Arin Wildani $^{1}$, Agus Budiyono ${ }^{2}$, Mohammad Lutfiadi $^{3}$ \\ arinwildani@uim.ac.id \\ ${ }^{123}$ Pendidikan Fisika Universitas islam Madura, Jawa Timur, Indonesia
}

Received: 3 Juni 2021

Revised: 4 Juni 2021

Accepted: 17 Juni 2021

\begin{abstract}
The purpose of this study is to describe the increase in students' cognitive abilities as an effect of providing problem based learning treatment based on the evaluation of Physics Playing Cards. The method used in the implementation of this research uses a quasi-experimental method, where there is one class as the experimental class and another class as the control class. This study used two sample classes at the State Senior High School (SMAN) 4 Pamekasan which were taken randomly. This research instrument uses a cognitive ability test on wave material. Research data were taken before and after learning. Data were analyzed using $N$-gain to find out the increase in students' cognitive abilities. The results showed that there was a high increase in students' cognitive abilities in the experimental class and a moderate increase in students' cognitive abilities in the control class. This research can be concluded that the use of evaluation based on Physics Playing Cards in the problem based learning model has increased higher than the problem based learning model.
\end{abstract}

Keyword: cognitive abilities, problem based learning, Physics Playing Cards, students

\begin{abstract}
Abstrak: Tujuan dalam penelitian ini untuk mendeskripsikan peningkatan kemampuan kognitif siswa sebagai efek dari pemberian perlakuan problem based learning berbasis evaluasi Physics Playing Cards. Metode yang digunakan dalam pelaksanaan penelitian ini menggunakan metode kuasi ekperimen, dimana ada satu kelas sebagai kelas eksperimen serta satu kelas lagi sebagai kelas kontrol. Penelitian ini menggunakan dua kelas sampel di Sekolah Menengah Atas negeri (SMAN) 4 Pamekasan yang diambil secara acak kelas. Instrument penelitian ini menggunakan tes kemampuan kognitif pada materi gelombang. Data penelitian diambil pada saat sebelum pembelajaran dan pada saat setelah pembelajaran. Data dianalisis menggunakan $N$-gain untuk mengetahuai peningkatan kemampuan kognitif siswa. Hasil penelitian menunjukkan terjadi peningkatan yang tinggi kemampuan kognitif siswa pada kelas ekperimen dan peningkatan yang sedang kemampuan kognitif siswa pada kelas kontrol. Penelitian ini dapat disimpulkan bahwa penggunaan evaluasi berbasi Physics Playing Cards pada model problem based learning mengalami peningkatan lebih tinggi dibandingkan dengan model problem based learning saja.
\end{abstract}

Kata kunci: kemampuan kognitif, problem based learning, Physics Playing Cards, siswa

\section{PENDAHULUAN}

Kemampuan kognitif siswa di tingkat Sekolah Menengah Atas (SMA) menjadi salah satu kompetensi yang harus dicapai selain kemampuan afektif dan psikomotorik. Kemampuan kognitif atau dalam kurikulum 2013 dikenal dengan pengetahuan, yakni setiap siswa harus mampu menguasai pengetahuan agar mampu mengikuti proses pembelajaran di sekolah. 
Pada dasarnya kemampuan kognitif setiap individu pastilah berbeda. Kemampuan siswa dalam memahami dan menangkap materi yang disampaikan oleh guru pun akan menjadi beraneka ragam. Siswa yang berhasil dalam proses pembelajaran, maka siswa memiliki kematangan berpikir kognitif, sehingga siswa diharapkan mampu mengaplikasikan mater fisika dalam kehidupan sehari-hari. Hal ini dikarenakan siswa sudah mampu dalam mengingat, memahami, mengaplikasikan, menganalisis, mengevaluasi dan mencipta suatu konsep materi (Anderson \& Krathwohl, 2015). Siswa merupakan objek yang berkaitan langsung dengan proses pembelajaran sehingga perkembangan kognitif sangat menentukan keberhasilan siswa di sekolah (Basri, H, 2018).

Tuntutan di atas juga berlaku bagi pelajaran fisika, proses belajar dan mengajar pada materi fisika hendaknya mampu meningkatkan kemampuan kognitif siswa. Salah satu disiplin ilmu yang sangat penting seseorang pelajari dalam pendidikan adalah ilmu Fisika. Karena ilmu Fisika adalah salah satu disiplin ilmu yang sangat berpengaruh terhadap kemajuan peradaban manusia, diantaranya di bidang teknologi yang saat ini menjadi tumpuan manusia dalam menunjang kehidupannya, agar lebih cepat dan mudah dalam mengerjakan sesesuatu. Pembelajaran Fisika adalah proses pembelajaran yang mempelajari alam dan kejadiannya, yang menyangkut tentang pemahaman ide, hukum, teori dan hakikat/asas beserta kepandaian dalam melakukan proses: mengukur, eksperimen, bernalar diskusi dan permasalahan sains. Untuk itu dalam mempelajari fisika tidak cukup dengan belajar dari buku atau mendengarkan penjelasan dari guru tetapi juga membutuhkan media untuk mempermudah memahami materi Fisika, termasuk dengan menggunakan game dalam proses pembelajaran berlangsung (Widiya, S, 2020).

Berdasarkan hasil observasi yang peneliti lakukan di lokasi penelitian, menunjukkan kemampuan kognitif siswa masih belum optimal, hal ini terlihat dari hasil ulangan harian yang masih banyak siswa belum mendapatkan nilai sesuai dengan KKM. Kemampuan kognitif siswa akan dicapai manakala proses belajar dan pembelajaran yang dijalankan mampu memberikan proses belajar yang bermakna yakni siswa mampu menghubungkan pengetahuan lama dengan pengetahuan barunya. Proses belajar mengajar sejatinya mendidiki, bukan sekedar mentransfer ilmu pengetahuan, diperlukan komunikasi aktif antara guru dan siswa yang seharusnya terjadi dua arah. Dengan demikian proses belajar mengajar akan menemukan hakikat belajar secara utuh. Disisi lain siswa akan merasa menjalani pembelajaran sebagai pusat bukan hanya sebatas objek pembelajar. 
Alternatif pembelajaran yang dapat menyelesaikan persoalan tersebut adalah dengan memilih model pembelajaran yang mampu memfasilitasi peningkatan kemampuan kognitif siswa. Pembelajaran yang dapat menfasilitasi permasalahan tersebut adalah Problem Based Learning (PBL) atau biasa disebut pembelajaran berbasis masalah. PBL merupakan pembelajaran yang menyodorkan suatu permasalahan di awal pembelajaran sehingga mampu diselesaikan oleh siswa di akhir pembelajaran. PBL efektif mampu meningkatkan hasil belajar fisika utamanya dalam ranah kognitif siswa (Komariah, N., M, M., Yusuf, I., \& Widyaningsih, S. W, 2019). PBL menuntut aktivitas mental siswa untuk memahami suatu konsep pembelajaran melalui situasi dan masalah yang disajikan pada awal pembelajaran dengan tujuan untuk melatih siswa menyelesaikan masalah dengan menggunakan pendekatan pemecahan masalah. Pemecahan masalah berhubungan dengan kemampuan berpikir kritis karena berpikir kritis merupakan suatu proses yang digunakan ketika mendatangkan (memunculkan) suatu ide baru dengan menggabungkan ide-ide yang sebelumnya dilakukan (Kono, R, 2016).

Dalam upaya pencapaian kemampuan kognitif yang lebih optimal, tentunya perlu adanya media pembelajaran yang mampu memudahkan siswa untuk dapat menerima pelajaran fisika lebih mudah. Diantaranya dengan memberikan media pembelajaran berbasis permainan. Media pembelajaran berbasis permainan sangat memberikan dampak yag positif terhadap hasil belajar utamanya dalam ranah kognitif (Budiyono, A., Hair, M. A., Wildani, A., \& Firdausiyah, F, 2020).

Media pembelajaran berbasis permainan akan membantu siswa dalam memberikan solusi terhadap masalah yang diberikan saat pembelajaran, labih lagi permainan diberikan pada saat evaluasi, sehingga siswa merasa tidak dievaluasi namun merasa sedang bermain tapi yang bermakna (Budiyono et al., 2020). Salah satu permainan yang bisa dijadikan bahan evaluasi kepada siswa adalah Physics Playing Cards (PPC). Permainan PPC dalam pembelajarn mampu memberikan peningkatan hasil belajar siswa (Sukarsih et al., 2018). PPC juga memberikan pengaruh yang baih terhadap penguasaan konsep fisika siswa (Lutfiyadi \& Budiyono, 2018).

PBL berbantuan PPC merupakan salah satu jawaban untuk meningkatkan kemampuan kognitif siswa. Dengan PBL yang dirancang perrmasalahan di awal serta permainan PPC sebagai bahan evaluasi bagi siswa akan berkontribusi baik terhadap kemampuan kognitif siswa. 


\section{METODE PENELITIAN}

Penelitian ini menggunakan penelitian kuasi eksperimen, adapun desain penelitian menggunakan satu kelas eksperimen dan satu kelas pembanding sebagai kelas kontrol dengan adanya tes baik sebelum dan sesudah pembelajaran. Desain penelitian ini dapat digambarkan seperti gambar 1 (Sugiono, 2017).

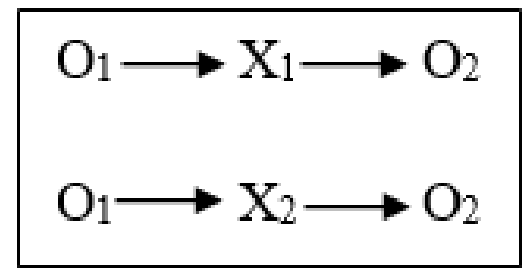

Gambar 1. Desain Penelitian

Keterangan:

$\mathrm{O}_{1}$ : Tes awal kemampuan kognitif siswa.

$\mathrm{O}_{2}$ : Tes akhir kemampuan kognitif siswa.

$\mathrm{X}_{1}$ : Perlakuan yang diberikan pada kelas eksperimen berupa model PBL berbasis evaluasi PPC

$\mathrm{X}_{2}$ : Perlakuan yang diberikan pada kelas kontrol model PBL saja.

Pada penelitian ini mengggunakan instrumen tes kognitif berupa tes uraian yang mencakup ranah kognitif $\mathrm{C} 1$ sampai $\mathrm{C} 4$ yang diberikan pada saat pretest dan postest. Soalsoal dalam tes ini dibuat oleh peniliti yang sebelumnya telah dilakukan validasi.

Setelah data pretest dan postest diperoleh, dilanjutkan dengan menganalisis data pretest dan posttes menggunakan persamaan gain yang dinormalisasi ( $\mathrm{N}$-gain) guna menentukan tingkat peningkatan kemampuan kognitif siswa. Adapun persamaan $\mathrm{N}$-gain sebagai berikut (Hake, 1999).

$$
\langle g\rangle=\frac{\text { skor postest-skor pretest }}{\text { skor maksimum-skor pretest }}
$$

Setelah data dianalisis, proses selanjutnya adalah menginterpretasikan data $\mathrm{N}$-gain dengan ketentuan jika nilai $\mathrm{N}$-gain kurang dari 0,3 maka peningkatan tergolong rendah, jika nilai $\mathrm{N}$-gain diantara 0,3 sampai dengan kurang dari 0,7 maka peningkatan tergolong sedang, serta jika nilai $\mathrm{N}$-gain diatas atau sama dengan 0,7 maka peningkatan tergolong tinggi. 


\section{HASIL DAN PEMBAHASAN}

Kemampuan kognitif awal siswa diperoleh dari hasil pretest dan kemampuan kognitif akhir siswa diperoleh dari hasil posttest yang keduanya diberikan pada masing-masing kelas. Hasil rekap kemampuan kognitif siswa dapat disajikan pada tabel 3.

Tabel 3. Rekapitulasi hasil tes kemampuan kognitif siswa

\begin{tabular}{ccc}
\hline Kelas & Pretest (\%) & Posttest (\%) \\
\hline PBL dengan & 32 & 90 \\
Evaluasi PPC & 32 & 79 \\
PBL & 38 & \\
\hline
\end{tabular}

Berdasarkan tabel 3 menunjukkan hasil persentase kemampuan awal kelas eksperimen dan kelas kontrol sebesar 32\% dan 38\%, data ini menginterpretasikan bahawa antara kedua kelas dapat dianggap memiliki kemampuan kognitif yang sama, walaupun kelas kontrol sedikit lebih besar. Adapun kemampuan akhir siswa menunjukkan perbedaan antara kelas ekperimen dan kelas kontrol yakni sebesar 90\% dan $79 \%$. Data tabel 3 terlihat pada kelas eksperimen memiliki kekampuan akhir yang lebih tinggi dari pada kelas kontrol, artinya adanya permainan PPC memberikan peningkatan yang lebih baik dari pada tanpa adanya permainan PPC. Untuk mengetahui seberapa besar peningkatan kemampuan kognitif dianalisis menggunakan N-gain yang disajikan pada tabel 4.

Tabel 4. Data Hasil analisis N-Gain

\begin{tabular}{ccc}
\hline Kelas & PBL berbasis PPC & PBL \\
\hline Pretest & 32,1875 & 38,375 \\
Posttes & 89,9375 & 79,125 \\
N-gain & 0,850511 & 0,661706 \\
Kategori & Tinggi & Sedang \\
\hline
\end{tabular}

Tabel 4 menunjukkan perbedaan hasil peningkatan kemampuan kognitif siswa efek dari permainan PPC pada PBL. Pengikatan kemampuan kognitif siswa berada pada kategori tinggi pada kelas eksperimen, sedangkan peningkatan kemampuan kognitif siswa di kelas kontrol berada pada kategori sedang. Hal ini dikarenakan adanya peran permainan PPC yang diberikan pada PBL sehingga kemampuan kognitif siswa lebih baik. Adanya permainan PPC pada PBL dapat memberikan pengaruh yang besar terhadap kemampuan kognitif siswa.

Adapun bentuk evaluasi berbasis PPC dapat dijabarkan sebagai berikut:

1) Membentuk kelompok yang beranggotakan 4-5 orang. 
2) Salah satu pemain mengocok kartu kemudian membagikan sebanyak 4 kartu tiap pemain dan satu kartu dibuka ditengah-tengah pemain serta sisa kartu ditumpuk dan diletakkan ditengah-tengah pemain sebagai kartu cadangan.

3) Untuk memulai permainan para pemain harus melakukan hompimpah dan yang menang akan memulai permainan terlebih dahulu.

4) Pemain pertama tersebut harus meletakkan kartu yang sejenis dengan kartu yang terbuka akan tetapi terlebih dahulu harus menjawab pertanyaan yang ada pada kartu yang terbuka, jika tidak bisa menjawab pertanyaannya maka pemain tersebut tidak diperbolehkan untuk meletakkan kartu dan akan diganti pemain kedua (sebelah kanan pemain pertama).

5) Apabila pemain tersebut tidak memiliki kartu yang sejenis dengan kartu yang terbuka maka pemain tersebut harus mencari kartu yang sejenis di tumpukan kartu cadangan.

6) Begitu juga dengan pemain selanjutnya harus meletakkan kartu yang sejenis dan harus menjawab pertanyaan yang ada pada kartu yang diletakkan pemain sebelumnya. Apabila tidak bisa menjawab maka tidak diperbolehkan meletakkan kartu dan digantikan pemain selanjutnya.

7) Jika tidak memiliki kartu yang sejenis maka harus mencari di tumpukan kartu cadangan.

8) Pemain dengan poin kartu tertinggi maka akan memenangkan permainan pada putaran tersebut dan berhak memulai permainan di putaran selanjutnya.

9) Pemain yang berhasil menghabiskan kartu terlebih dahulu maka akan menjadi pemenang dalam permainan ini serta akan membuat permainan berakhir.

10) Permainan juga dikatakan berakhir apabila waktu yang telah ditentukan telah habis, dan pemenagnya adalah pemain yang sisa kartunya paling sedikit.

Tahapan evaluasi yang menyenangkan dengan 10 langkah di atas ini tidak didapatkan oleh siswa di kelas kontrol. Kegiatan ini mampu memberikan dampak positif kepada kemampuan kognitif siswa. Siswa merasa tidak sedang dievaluasi namun dengan bermain siswa sudah menunjukkan kemampuannya dalam menguasai materi yang sedang dipelajari. Hasil penelitian ini menunjukkan kesamaan dengan hasil penelitian lainnya yang menyatakan evaluasi dengan permainan memberikan dampak positif kepada siswa (Budiyono et al., 2020; Sari et al., 2017; Suliyanah et al., 2021). Permainan PPC sudah sangat jelas memberikan dampak terhadap peningkatan kemampuan siswa dalam menguasasi pelajaran yang sedang dipelajari (Lutfiyadi \& Budiyono, 2018; Sukarsih et al., 2018). 


\section{SIMPULAN DAN SARAN}

Peningkatan kemampuan kognitif siswa diberikan pemebelajaran dengan model PBL berbasis evaluasi PPC sebesar 0,85 yang tergolong pada kategori tinggi. Dengan ini peneliti menyarankan untuk menggunakan model PBL dengan evaluasi PPC dapat ditingkatkan penggunaannya kepada siswa dengan materi fisika lainnya sehingga siswa mendapatkan variasi pembelajaran.

\section{DAFTAR PUSTAKA}

Anderson, L. W., \& Krathwohl, D. R. (2015). Kerangka Landasan Untuk Pembelajaran, Pengajaran, dan Asesmen. Pustaka Pelajar.

Budiyono, A., Hair, M. A., Wildani, A., \& Firdausiyah, F. (2020). Pengaruh Learning Cycle 5e Berbantuan Permainan Monopoli Fisika Berpoin (MOKAIN) Terhadap Penguasaan Konsep Peserta Didik SMA. Edu Sains: Jurnal Pendidikan Sains Dan Matematika, 8(2), 22-31. https://doi.org/10.23971/eds.v8i2.1481

Komariah, N., M, M., Yusuf, I., \& Widyaningsih, S. W. (2019). Pengaruh Penerapan Model Pbl Berbantuan Media Google Classroom Terhadap Hots, Motivasi Dan Minat Peserta Didik. Silampari Jurnal Pendidikan Ilmu Fisika, 1(2), 102-113. https://doi.org/10.31540/sjpif.v1i2.788

Kono, R. (2016). Pengaruh Model Problem Based Learning (PBL) Terhadap Pemahaman Konsep Biologi Dan Keterampilan Berpikir Kritis Siswa Tentang Ekosistem Dan Lingkungan Di Kelas X SMA Negeri 1 Sigi. JSTT, 5(1).

Lutfiyadi, M., \& Budiyono, A. (2018). Pengaruh Model Pembelajaran Problem Based Learning Berbantuan Media Permainan Kareka (Kartu Remi Fisika) Terhadap Penguasaan Konsep Fisika Siswa SMA. National Conference on Mathematics, Science and Education (NACOMSE), 1(01), 247-254.

Miswati, M., Amin, A., \& Lovisia, E. (2020). Pengembangan Media Pembelajaran Power Point Macro Berbasis Problem Based Learning Materi Besaran dan Pengukuran Sebagai Sumber Belajar Siswa Kelas X. Silampari Jurnal Pendidikan Ilmu Fisika, 2(2), 77-91. https://doi.org/10.31540/sjpif.v2i2.984

Parasamya, C. E., Wahyuni, A., \& Hamid, A. (2017). Upaya Peningkatan Hasil Belajar Fisika Siswa Melalui Penerapan Model Pembelajaran Problem Based Learning (PBL). Jurnal Ilmiah Mahasiswa Pendidikan Fisika, 2(1), 42-49. 
Sari, W., Ar, M., \& Melvina. (2017). Pengaruh Pendekatan SAVI (Somatic, Auditory, Visual, And Intellectual) Dengan Menggunakan Media Education Card Terhadap Pemahaman Siswa. Jurnal Ilmiah Mahasiswa Pendidikan Fisika, 2(1), 108-113.

Sugiyono. 2017. Metode Penelitian Kuantitatif Kualitatif R\&B. Bandung: Aflabeta.

Sukarsih, N. K. A., Wardhani, R. R. A. A. K., \& Mashuri, M. T. (2018). Pengembangan Kartu Remi Kimia Menggunakan Model Pembelajaran Tgt (Teams Games Tournament)Terhadap Hasil Belajar Siswa Pada Materi Pokok Sistem Koloid Kelas Xi Sma Korpri Banjarmasin. Dalton : Jurnal Pendidikan Kimia dan Ilmu Kimia, 1(1), Article 1. https://doi.org/10.31602/dl.v1i1.1497

Suliyanah, Deta, U. A., Kurniawan, F. K., Lestari, N. A., Yantidewi, M., Jauhariyah, M. N. R., \& Prahani, B. K. (2021). Literature Review on The Use of Educational Physics Games in Improving Learning Outcomes. Journal of Physics: Conference Series, 1805(1), 012038. https://doi.org/10.1088/1742-6596/1805/1/012038

Widiya, S. (2020). Pengembangan Media Pembelajaran Uno Physics Card Berbasis Mind Mapping pada Pembelajaran Fisika Siswa SMP (Doctoral dissertation, UIN Raden Intan Lampung). 